


\title{
Radical-cation salt with novel BEDT-TTF packing motif containing tris(oxalato)germanate(IV)
}

\author{
Jordan R. Lopez, ${ }^{[a]}$ Hiroki Akutsu ${ }^{[\mathrm{b}]}$ and Lee Martin ${ }^{[\mathrm{a}]^{*}}$
}

[a] School of Science and Technology, Nottingham Trent University, Clifton Lane, Clifton, Nottingham, NG11 8NS, UK. Tel: +44 (0)1158483128; E-mail: lee.martin@ntu.ac.uk

[b] Department of Chemistry, Graduate School of Science, Osaka University, 1-1 Machikaneyama-cho, Toyonaka, Osaka 560-0043, Japan

\begin{abstract}
The synthesis, crystal structure and resistivity of a new semiconducting BEDT-TTF radical-cation salt containing the tris(oxalato)germanate(IV) anion is reported. BEDT$\mathrm{TTF}_{4}\left[\mathrm{Ge}\left(\mathrm{C}_{2} \mathrm{O}_{4}\right)_{3}\right] .0 .5$ dichloromethane crystallizes in the space group $P 2_{1} / c, a=18.322(7), b=$ 11.919(4), $c=32.746(11) \AA, \beta=105.797(5)^{\circ}, V=6881(4) \AA^{3}, T=295(1) \mathrm{K}, Z=4$. Electrical resistivity measurements show that BEDT-TTF $\left[\mathrm{Ge}\left(\mathrm{C}_{2} \mathrm{O}_{4}\right)_{3}\right] \cdot 0.5$ dichloromethane is a semiconductor with an activation energy of $0.224 \mathrm{eV}$ and room temperature resistivity of 212 ohm cm.
\end{abstract}

\section{Introduction}

Radical-cation salts of BEDT-TTF with tris(oxalato)metallate anions represent a large family of materials which combine magnetism and conductivity together in the same lattice. Salts having the formula (BEDT-TTF $)_{4}\left[\left(\right.\right.$ cation) $\left.\mathrm{M}^{3+}\left(\mathrm{C}_{2} \mathrm{O}_{4}\right)_{3}\right]$. Guest ${ }^{1}$ show a wide range of properties depending upon the cation ${ }^{2}\left(\mathrm{~K}^{+}, \mathrm{H}_{3} \mathrm{O}^{+}, \mathrm{Na}^{+}, \mathrm{Rb}^{+}, \mathrm{NH}_{4}{ }^{+}, \mathrm{Metal}^{2+}\right)$ and Metal $^{3+}\left(\mathrm{Fe},{ }^{3} \mathrm{Cr},{ }^{4} \mathrm{Ga},{ }^{5} \mathrm{Al},{ }^{6} \mathrm{Co}^{6}{ }^{6} \mathrm{Ru}^{7}\right)$. Changing the guest molecule has a significant effect on the packing motif of the conducting donor layer through hydrogen bonding interactions with the terminal ethylene groups on the BEDT-TTF molecules. Superconductivity is observed in some of the salts having a $\beta^{\prime}{ }^{\prime}$ donor packing motif, but this superconductivity can be supressed by changing the size and shape of the guest solvent molecule. ${ }^{8}$ Some salts remain metallic down to low temperatures, others show a metal-insulator transition. For larger guest molecules which do not fit symmetrically within the anion layer different interactions with neighbouring donor layers leads to different donor packing modes being observed in alternate layers. This produces bilayered radical-cation salts with $\alpha$-pseudo- $k^{9}$ or $\alpha-\beta^{\prime}{ }^{\prime}{ }^{10}$ donor packing.

There are only three previous examples in this family which contain the tris(oxalato)germanate(IV) anion. All three are semiconductors with novel packing arrangements of both the BEDT-TTF layers and the tris(oxalato)germanate anions. Use of an anion with a charge of 2- gives salts that are not isostructural with the 3- examples in which the tris(oxalato)metallate(III) anions and cations form 2D honeycomb sheets.

(BEDT-TTF $)_{2}\left[\mathrm{Ge}\left(\mathrm{C}_{2} \mathrm{O}_{4}\right)_{3}\right] \cdot \mathrm{C}_{6} \mathrm{H}_{5} \mathrm{CN}^{11}$ does not contain alternating anion and cation layers but instead has face-to-face BEDT-TTF dimers in a checkerboard arrangement with $\left[\mathrm{Ge}\left(\mathrm{C}_{2} \mathrm{O}_{4}\right)_{3}\right]^{2-}$ anions. There is a separate layer consisting of the benzonitrile guest solvent molecules.

$(\text { BEDT-TTF })_{7}(\text { dichloromethane })_{2}\left[\mathrm{Ge}\left(\mathrm{C}_{2} \mathrm{O}_{4}\right)_{3}\right]_{2} \cdot \mathrm{H}_{2} \mathrm{O}^{12}$ has distinct donor and anion layers. The anion layer consists of columns of $\left[\mathrm{Ge}\left(\mathrm{C}_{2} \mathrm{O}_{4}\right)_{3}\right]^{2-}$ segregated into $\Delta$ and $\Lambda$ enantiomers separated by dichloromethane molecules.

Crystals of (BEDT-TTF $)_{5}\left[\mathrm{Ge}\left(\mathrm{C}_{2} \mathrm{O}_{4}\right)_{3}\right]_{2}{ }^{12}$ have been obtained from several different solvents, but of note is that when using $(R)-(-)$-carvone a Flack parameter of $0.43(3)$ is observed. Several other examples have been reported where the use of $(R)-(-)$-carvone as solvent has produced BEDT-TTF salts with an excess of one enantiomer of $\left[\mathrm{Cr}\left(\mathrm{C}_{2} \mathrm{O}_{4}\right)_{3}\right]^{3-}$ or $\left[\mathrm{Al}\left(\mathrm{C}_{2} \mathrm{O}_{4}\right)_{3}\right]^{3-}$. $^{13}$ 
All three of the previously reported radical-cation salts containing $\mathrm{Ge}(\mathrm{IV})$ were synthesised from the ammonium salt of tris(oxalato)germanate(IV). In all three cases the ammonium cation is not included in the radical-cation salt, unlike when using ammonium salts of $\left[\mathrm{M}\left(\mathrm{C}_{2} \mathrm{O}_{4}\right)_{3}\right]^{3-}$ where the ammonium (or hydroxonium) cation is included in the majority of cases. This produces a hexagonal packing of the anion layer which can lead to metallic and even superconducting depending on the donor packing arrangement through subtle hydrogen bonding interactions between the donor and anion layer. It has been previously observed that changing from the ammonium to caesium cation with $\left[\mathrm{M}\left(\mathrm{C}_{2} \mathrm{O}_{4}\right)_{3}\right]^{3-}$ leads to a change in the anion layer packing. The caesium cation in not included in the radical-cation salt and hexagonal packing of the tris(oxalato) anions is not found, instead hydrogen-bonded chains of water molecules are present. ${ }^{14}$

We have attempted to introduce counter cations other than ammonium into the lattice with $\left[\mathrm{Ge}\left(\mathrm{C}_{2} \mathrm{O}_{4}\right)_{3}\right]^{2-}$ to explore whether it is possible to obtain new materials through crystal engineering and if it is possible to obtain a hexagonal packing arrangement to the anion layer similar to that observed when using $\left[\mathrm{M}\left(\mathrm{C}_{2} \mathrm{O}_{4}\right)_{3}\right]^{3-}$.

We report here a new addition to this family of radical-cation salts synthesised from the caesium salt of tris(oxalato)germanate(IV) using the solvent dichloromethane. The caesium cation is not included in the radical-cation salt but both the anion and donor packing obtained is novel in this family of materials.

\section{Experimental}

\section{Synthesis and purification of starting materials}

$\mathrm{Cs}_{2}\left[\mathrm{Ge}\left(\mathrm{C}_{2} \mathrm{O}_{4}\right)_{3}\right]$ was made by an adaptation of the method of Arvedson and Larson with cesium oxalate. ${ }^{15}$ BEDT-TTF, dichloromethane and 18-crown-6 were purchased from Sigma Aldrich and used as received.

\section{Synthesis of BEDT-TTF $4\left[\mathrm{Ge}\left(\mathrm{C}_{2} \mathrm{O}_{4}\right)_{3}\right] \cdot 0.5$ dichloromethane (I)}

Crystals of I were grown on platinum electrodes by electrocrystallisation in $40 \mathrm{ml} \mathrm{H}$ shaped electrochemical cells. Platinum electrodes were cleaned by applying a voltage across the electrodes in $1 \mathrm{M} \mathrm{H}_{2} \mathrm{SO}_{4}$ in each direction to produce $\mathrm{H}_{2}$ and $\mathrm{O}_{2}$ at the electrodes, then washed with distilled water and thoroughly dried.

A solution of $\mathrm{Cs}_{2}\left[\mathrm{Ge}\left(\mathrm{C}_{2} \mathrm{O}_{4}\right)_{3}\right]$ (100mg), 18-crown-6 (200mg), dichloromethane (40ml) and 3 drops of distilled water was stirred until dissolution of the anion. This solution was then filtered into a $\mathrm{H}$-cell containing BEDT-TTF $(10 \mathrm{mg})$ in the base of the anode compartment. The $\mathrm{H}$-cell was then attached to a constant current source $(0.1 \mu \mathrm{A})$ in a dark box on a vibration-free table. After 1 week a large number of black rhombus shaped crystals had formed an evenly distributed layer around electrode.

\section{Transport measurements.}

Four-probe DC transport measurements were made on crystals of I using a HUSO HECS 994C multi-channel conductometer. Gold wires (15 $\mu \mathrm{m}$ diameter) were attached to the crystal with gold conductive cement. The attached wires were connected to an integrated circuit plug with gold conductive cement.

\section{Crystal data}

Crystal data: I: $\mathrm{C}_{46.5} \mathrm{H}_{33} \mathrm{Ge}_{1} \mathrm{O}_{12} \mathrm{~S}_{32} \mathrm{Cl}_{1}, M=1917.73$, brown plate, $a=18.322(7), b=$ 11.919(4), $c=32.746(11) \AA, V=6881(4) \AA^{3}, T=295(1) \mathrm{K}$, space group $P 2_{1} / \mathrm{c}, Z=4, \mu=$ $1.512 \mathrm{~mm}^{-1}$, reflections collected $=47706$, independent reflections $=15195, R 1=$ $0.0636, w R 2=0.1634$ (all data). X-Ray single crystal diffraction measurements were performed on a Rigaku Mercury 2 CCD rotating anode diffractometer configured with Rigaku MicroMax-007HF generator and VariMax confocal mirror using MoKa radiation $(\lambda$ $=0.71073 \AA$ ). Structures were solved by direct methods, SIR92, and refined by fullmatrix least squared techniques based on $\mathrm{F}^{2}$ (SHELX97).

CCDC 1051553 contains supplementary X-ray crystallographic data for I. This data can be obtained free of charge via http://www.ccdc.cam.ac.uk/conts/retrieving.html, or from the 
Cambridge Crystallographic Data Centre, Union Road, Cambridge, CB2 1EZ; fax(+44) 1223336-033 or email: deposit@ccdc.cam.ac.uk.

\section{Results and Discussion}

The asymmetric unit of BEDT-TTF $4\left[\mathrm{Ge}\left(\mathrm{C}_{2} \mathrm{O}_{4}\right)_{3}\right]$.0.5dichloromethane (I) consists of four BEDT-TTF molecules, one tris(oxalato)germanate anion and half a dichloromethane molecule, which is located about the centre of symmetry and so is disordered. (Fig. 1). There are discrete layers with tris(oxalato)germanate anions and dichloromethane molecules occupying one layer, and the donor occupying the other (Fig. 2).

The BEDT-TTF stacks consist of repeating blocks of the four crystallographically independent molecules (Fig. 3). The central $\mathrm{C}=\mathrm{C}$ bonds of each of the BEDT-TTF are directly aligned with each other within the block of four. The BEDT-TTF molecules in the next block of four are shifted with the central $\mathrm{C}=\mathrm{C}$ aligned with a six-membered ring of the BEDTTTFs in the neighbouring block. The two central BEDT-TTFs in each block of four (B and $C$ ) have eclipsed ethylene groups at both ends, whilst the two outer BEDT-TTFs (A and D) are bent and have an eclipsed ethylene at one end and a boat conformation at the other end (Fig. 3).

Each block of four BEDT-TTF molecules forms several short side-to-side S...S contacts with BEDT-TTF molecules outside of the parent block and four face-to-face contacts within each block (Table 1, Fig. 4). Three of the face-to-face S...S contacts are between the central BEDT-TTF molecules B and C (S13...S21: $3.457 \AA$, S11...S19: $3.452 \AA$, S12...S20: 3.579 $\AA)$ and the fourth is between BEDT-TTF molecules C and D (S19...S27: $3.518 \AA$ ).

Table 1 Close S...S contacts below the sum of the van der Waals radii $(<3.6 \AA$ ).

\begin{tabular}{|c|c|}
\hline S...S & Distance /Å \\
\hline Face-to-face & \\
\hline S11...S19 & 3.452 \\
\hline $\mathrm{S} 12 \ldots \mathrm{S} 20$ & 3.579 \\
\hline S13...S21 & 3.457 \\
\hline S19...S27 & 3.518 \\
\hline \multicolumn{2}{|l|}{ Side-to-side } \\
\hline $\mathrm{S} 1 \ldots \mathrm{S} 22$ & 3.417 \\
\hline $\mathrm{S} 2 \ldots \mathrm{S} 21$ & 3.400 \\
\hline $\mathrm{S} 2 \ldots \mathrm{S} 23$ & 3.446 \\
\hline S6...S9 & 3.408 \\
\hline S7 ...S18 & 3.435 \\
\hline $\mathrm{S} 10 \ldots \mathrm{S} 13$ & 3.446 \\
\hline $\mathrm{S} 10 \ldots \mathrm{S} 15$ & 3.515 \\
\hline $\mathrm{S} 19 \ldots \mathrm{S} 31$ & 3.469 \\
\hline S20...S32 & 3.541 \\
\hline $\mathrm{S} 23 \ldots \mathrm{S} 25$ & 3.399 \\
\hline S23...S27 & 3.517 \\
\hline S27...S29 & 3.525 \\
\hline $\mathrm{S} 27 \ldots \mathrm{S} 31$ & 3.514 \\
\hline $\mathrm{S} 28 \ldots \mathrm{S} 30$ & 3.575 \\
\hline $\mathrm{S} 28 \ldots \mathrm{S} 32$ & 3.545 \\
\hline
\end{tabular}


The charge on each donor, $Q$, has been approximated according to the method of Kepert et. al. ${ }^{16}$ by taking averages of the bond lengths of the BEDT-TTF molecules (Table 2). Using this method the charges of the central pair of BEDT-TTFs within a block are approximated at $1.01+$ for donor B and 1.15+ for donor C. The close face-to-face S...S contacts and approximated charges would suggest that donors $\mathrm{B}$ and $\mathrm{C}$ form a dimer (BEDT-TTF) ${ }_{2}{ }^{2+}$. The charge on the $\left[\mathrm{Ge}\left(\mathrm{C}_{2} \mathrm{O}_{4}\right)_{3}\right]$ anion is 2- therefore the total combined charge for (BEDT-TTF $)_{4}$ should be $2+$. Hence the outer donor molecules $A$ and $D$ should both be BEDT-TTF ${ }^{0}$. Using the bond lengths to approximate the charges we obtain values of $0.28+$ and $0.40+$ for $A$ and $D$, respectively, which may have an error owing to the bent nature of these two BEDT-TTF molecules.

Table 2 Average bond lengths and approximation of charge on the BEDT-TTF molecules of I. $\delta=(b+c)-(a+d), Q=6.347-7.463 \delta$.



\begin{tabular}{|lllllll|}
\hline Donor & $\mathbf{a} / \dot{\mathbf{A}}$ & $\mathbf{b} / \dot{\mathbf{A}}$ & $\mathbf{c} / \dot{\mathbf{A}}$ & $\mathbf{d} / \dot{\mathbf{A}}$ & $\mathbf{\delta}$ & $\mathbf{Q}$ \\
\hline BEDT-TTF A & 1.349 & 1.754 & 1.756 & 1.348 & 0.813 & $0.28^{+}$ \\
BEDT-TTF B & 1.388 & 1.726 & 1.742 & 1.365 & 0.715 & $1.01^{+}$ \\
BEDT-TTF C & 1.383 & 1.717 & 1.730 & 1.368 & 0.696 & $1.15^{+}$ \\
BEDT-TTF D & 1.356 & 1.745 & 1.755 & 1.347 & 0.797 & $0.40^{+}$ \\
\hline
\end{tabular}

Each anionic layer contains a 50:50 mixture of $\Delta$ and $\Lambda$ enantiomers of $\left[\mathrm{Ge}\left(\mathrm{C}_{2} \mathrm{O}_{4}\right)_{3}\right]^{2-}$. Dichloromethane molecules occupy a cavity in between a pair of $\Delta$ and $\Lambda$ enantiomers of $\left[\mathrm{Ge}\left(\mathrm{C}_{2} \mathrm{O}_{4}\right)_{3}\right]^{2-}$. Figure 5 shows the anion layer viewed down the a axis. Identical enantiomers form rows in the $b$ direction. In the $c$ direction the two enantiomers do not alternate but are arranged in the pattern $\Delta \triangle M M \triangle \triangle M \Lambda$ which leads to an overall racemic lattice. Two BEDTTTF molecules (A and $B$ ) form short contacts with separate $\left[\mathrm{Ge}\left(\mathrm{C}_{2} \mathrm{O}_{4}\right)_{3}\right]^{2-}$ anions $(\mathrm{O} 7 \ldots \mathrm{S} 7$ : $3.233 \AA$ Å, O11...S16: $3.202 \AA$ ).

Reproducible four-probe resistivity measurements were performed on crystals of I which has a room temperature resistivity of $212 \mathrm{ohm} \mathrm{cm}$ and shows semiconducting behaviour, $E_{a}=$ $0.224 \mathrm{eV}$ (Fig. 6). This is the lowest room temperature resistivity and the smallest activation energy observed compared to the previous three radical-cation salts of BEDT-TTF with the $\left[\mathrm{Ge}\left(\mathrm{C}_{2} \mathrm{O}_{4}\right)_{3}\right]^{2-}$ anion.

\section{Conclusions}

A novel radical-cation salt has been synthesised and characterised. (BEDT$\mathrm{TTF})_{4}\left[\mathrm{Ge}\left(\mathrm{C}_{2} \mathrm{O}_{4}\right)_{3}\right]$.0.5dichloromethane was synthesised from the caesium salt of tris(oxalato)germanate(IV) using the solvent dichloromethane, and is a different phase to that obtained from the ammonium salt. The structure has discrete layers of donor and anion, the donors forming stacks of four with a central dimer of (BEDT-TTF) ${ }_{2}{ }^{2+}$ sandwiched between two neutral donors.

\section{Acknowledgements}

LM thanks the Royal Society of Chemistry for a Journals Grant for International Authors. This work has been supported by the Royal Society [Research Grants (RG100853 and RG081209), International Exchange Scheme (IE130367), and International Joint Project (JP0869972)]. 


\section{Keywords: BEDT-TTF • semiconductor • conductivity • tris(oxalato)germanate}

\section{References}

1 E. Coronado and P. Day, Chem. Rev. 2004, 104, 5419.

2 L. Martin, H. Engelkamp, H. Akutsu, S-i. Nakatsuji, J-i. Yamada, P. Horton and M. Hursthouse, Dalton Trans., 2015, 44, 6219; L. Martin, H. Akutsu, P. N. Horton and M. B. Hursthouse, CrystEngComm, 2015, 17, 2783; L. Martin, P. Day, W. Clegg, R. W. Harrington, P. N. Horton, A. Bingham, M. B. Hursthouse, P. McMillan and S. Firth, J. Mater. Chem., 2007, 31, 3324; L. Martin, P. Day, S. A. Barnett, D. A. Tocher, P. N. Horton and M. B. Hursthouse, CrystEngComm, 2008, 2, 192; E. Coronado, J. R. Galán-Mascarós, C. J. Gómez-García and V. Laukhin, Nature, 2000, 408, 447.

3 M. Kurmoo, A. W. Graham, P. Day, S. J. Coles, M. B. Hursthouse, J. L. Caulfield, J. Singleton, F. L. Pratt, W. Hayes, L. Ducasse and P. Guionneau, J. Am. Chem. Soc., 1995, 117, 12209; E. Coronado, S. Curreli, C. Giménez-Saiz and C. J. Gómez-García, J. Mater. Chem., 2005, 15, 1429.

4 L. Martin, S. S. Turner, P. Day, F. E. Mabbs and E. J. L. McInnes, J. Chem. Soc., Chem. Commun., 1997, 1367; L. Martin, S. S. Turner, P. Day, K. M. A. Malik, S. J. Coles, and M. B. Hursthouse, J. Chem. Soc., Chem. Commun., 1999, 513; L. Martin, S. S. Turner and P. Day, Synth. Met., 1999, 102, 1638.

5 H. Akutsu, A. Akutsu-Sato, S. S. Turner, D. Le Pevelen, P. Day, V. Laukhin, A.-K. Klehe, J. Singleton, D. A. Tocher, M. R. Probert, and J. A. K. Howard, J. Am. Chem. Soc., 2002, 124 (42), 12430; T. Prokhorova, L. I. Buravov, E. B. Yagubskii, L.V. Zorina, S. V. Simonov, R. P. Shibaeva and V. N. Zverev, Eur. J. Inorg. Chem., 2014, 24, 3933.

6 L. Martin, S. S. Turner, P. Day, P. Guionneau, J. K. Howard, D. E. Hibbs, M. E. Light, M. B. Hursthouse, M. Uruichi and K. Yakushi, Inorg. Chem., 2001, 40, 1363.

7 T. G. Prokhorova, L. V. Zorina, S. V. Simonov, V. N. Zverev, E. Canadell, R. P. Shibaeva and E. B. Yagubskii, CrystEngComm, 2013, 15, 7048.

8 E. Coronado, S. Curreli, C. Giménez-Saiz and C. J. Gómez-García, Inorg. Chem., 2012, 51(2),1111; A. Akutsu-Sato, H. Akutsu, J-i. Yamada, S-i. Nakatsuji, S. S. Turner and P. Day, J. Mater. Chem., 2007, 17, 2497.

9 L. V. Zorina, S. S. Khasanov, S. V. Simonov, R. P. Shibaeva, V. N. Zverev, E. Canadell, T. G. Prokhorova and E. B. Yagubskii, CrystEngComm, 2011, 13, 2430.

10 H. Akutsu, A. Akutsu-Sato, S. S. Turner, P. Day, E. Canadell, S. Firth, R. J. H. Clark, J-i. Yamada and S-i. Nakatsuji, Chem. Commun., 2004, 18

11 L.Martin, S.S.Turner, P.Day, P.Guionneau, J.A.K.Howard, M.Uruichi and K. Yakushi, J. Mater. Chem., 1999, 9, 2731.

12 L. Martin, P. Day, S.-i. Nakatsuji, J.-i. Yamada, H. Akutsu, P. N. Horton and M. B. Hursthouse, Bull. Chem. Soc. Jpn, 2010, 83(4), 419.

13 L. Martin, H. Akutsu, P. N. Horton, M. B. Hursthouse, R. W. Harrington and W. Clegg, Eur.J.Inorg.Chem., 2015 DOI: 10.1002/ejic.201500092; L. Martin, P. Day, S.-i. Nakatsuji, J.-i. Yamada, H. Akutsu and P. Horton, CrystEngComm, 2010, 12, 1369-1372; L. Martin, S.-i. Nakatsuji, J.-i. Yamada, H. Akutsu and P. Day, J. Mater. Chem., 2010, 20, 2738.

14 L. Martin, P. Day, S. A. Barnett, D. A. Tocher, P. N. Horton and M. B. Hursthouse, CrystEngComm, 2008, 10, $192-196$.

15 P. Arvedson and E. M. Larsen, Inorganic Synthesis, 1966, 8, 35.

16 P. Guionneau, C. J. Kepert, D. Chasseau, M. R. Truter and P. Day, Synth. Met., 1997, 86, 1973. 
Fig. 1 Diagram of I with $50 \%$ thermal ellipsoids showing atomic labelling. BEDT-TTFs are labelled A to D from top to bottom

Fig. 2 Layered structure of I viewed down the $b$ axis.

Fig. 3 Side on view of the four crystallographically independent BEDT-TTF molecules viewed down the $b$ axis (top) and end on view showing packing of the donor layer (bottom). (BEDT-TTFs $A=$ red, $B=$ yellow, $C$ = magenta, and $\mathrm{D}=$ cyan $)$.

Fig. 4 BEDT-TTF layer of I viewed perpendicular to the $b$ axis showing blue lines to represent $S$...S contacts below the sum of the van der Waals radii $(<3.6 \AA)$.

Fig. 5 Spacefilling diagram displaying the orientation of anion and solvent molecules viewed down the a axis. Each solvent molecule occupies the cavity created between a pair of tris(oxalato)germanate enantiomers.

Fig. 6 Resistivity versus Temperature for I which has a room temperature resistivity of $212 \mathrm{ohm} \mathrm{cm}$ and an activation energy $0.224 \mathrm{eV}$. 


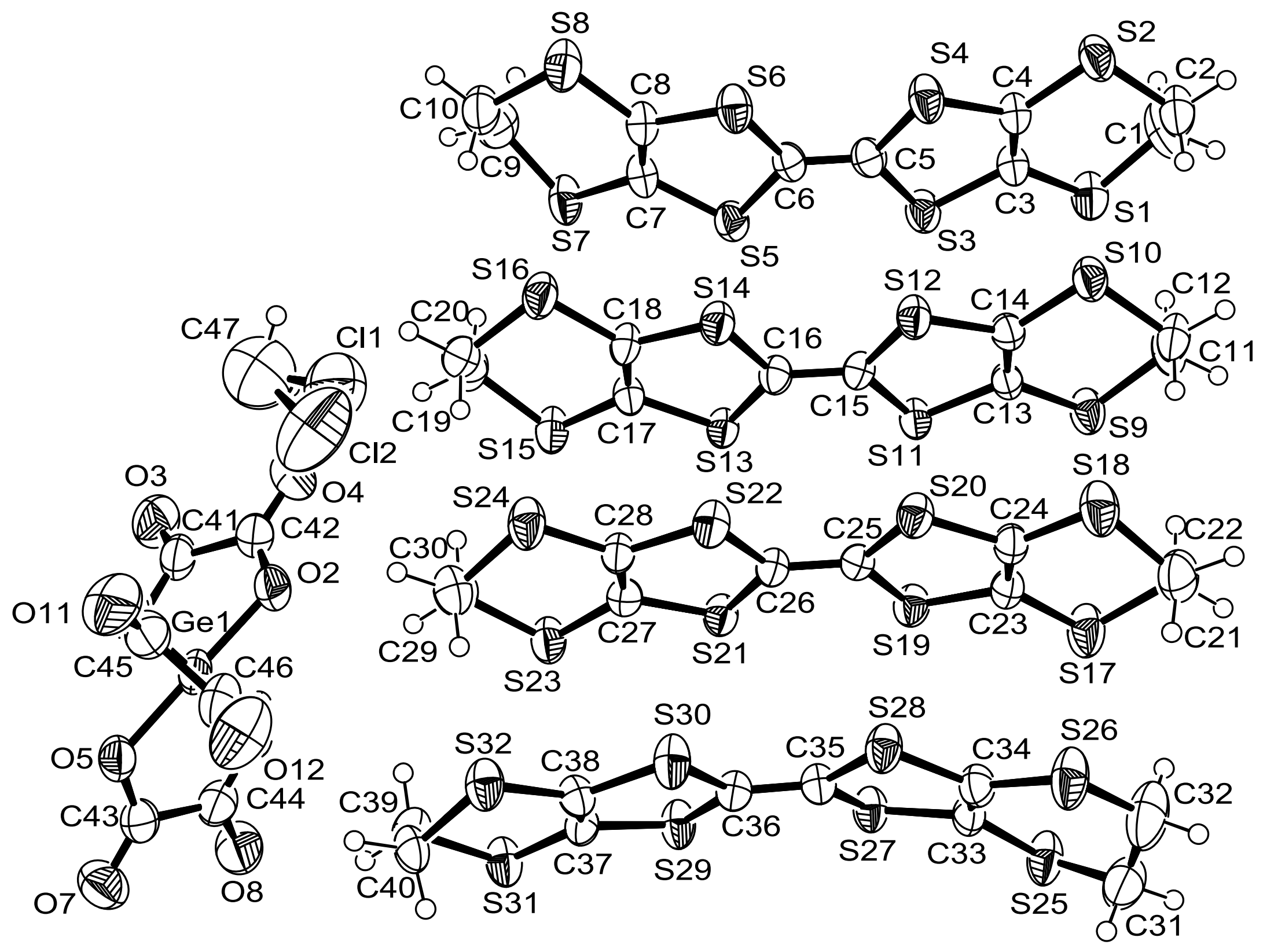


Figure 2
Click here to download high resolution image

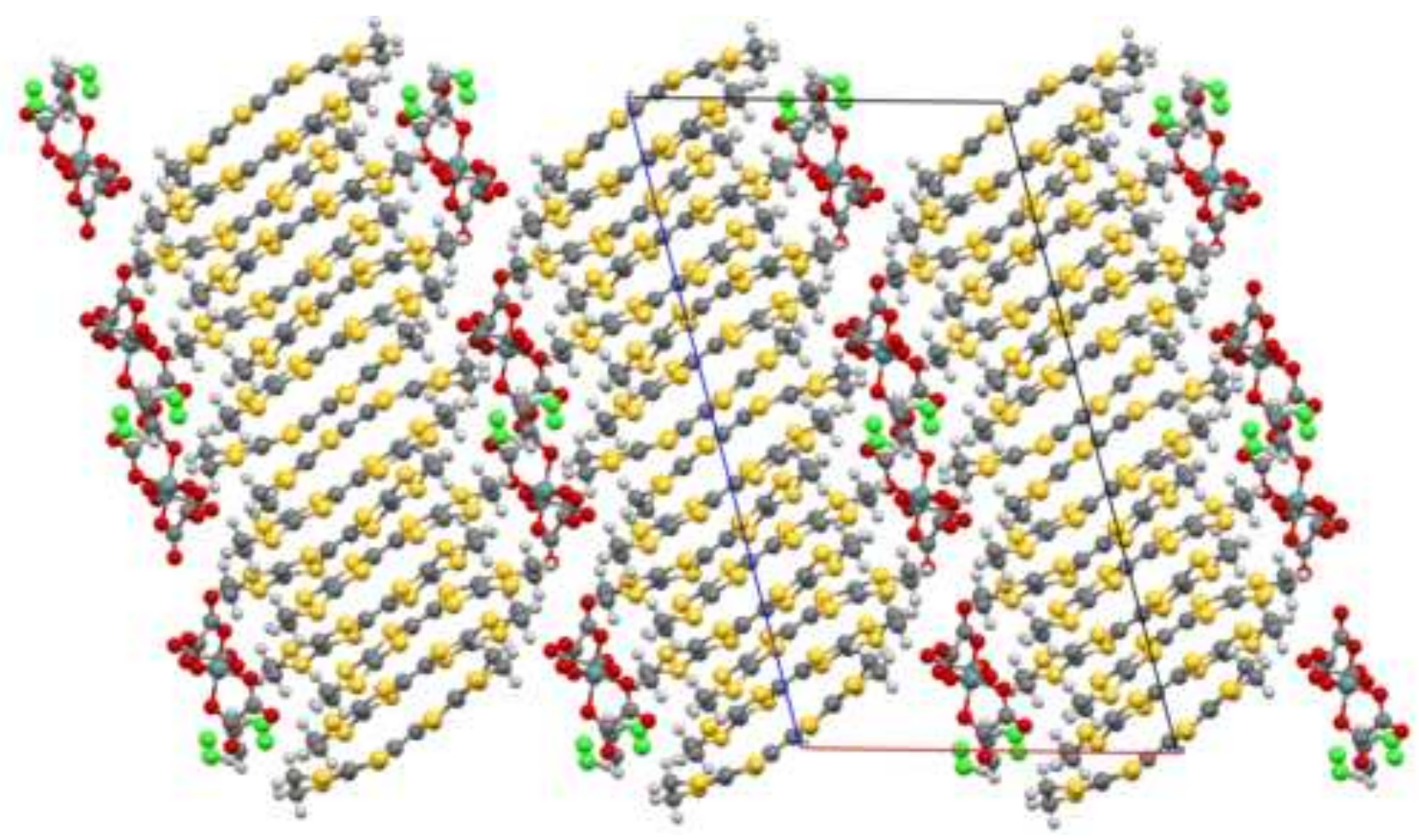




\section{Figure 3 top}

Click here to download high resolution image

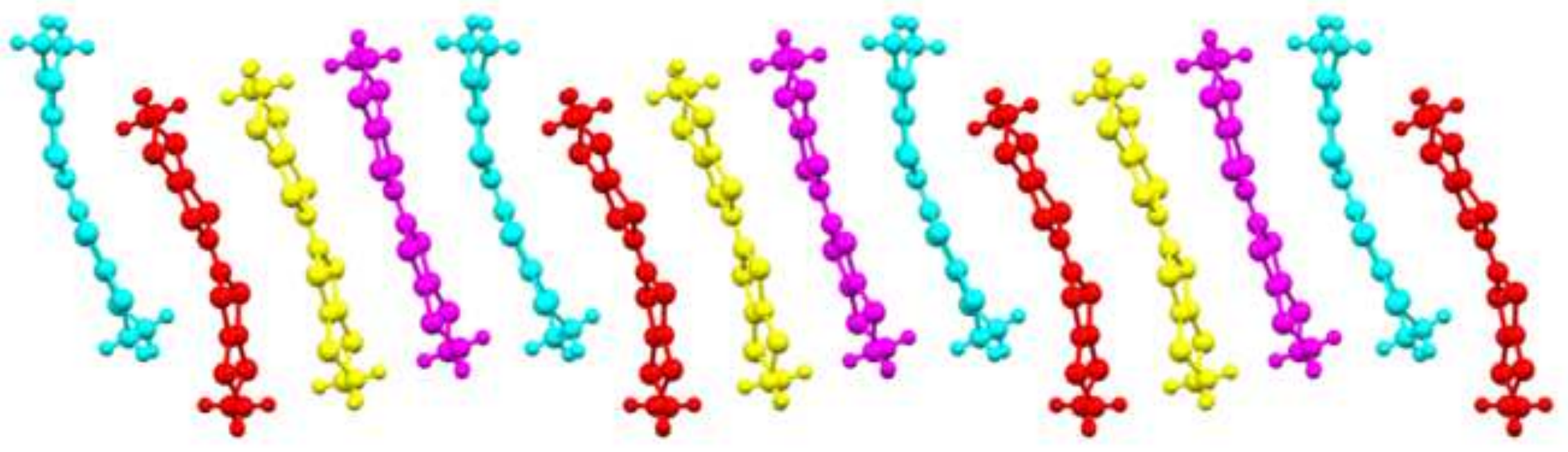




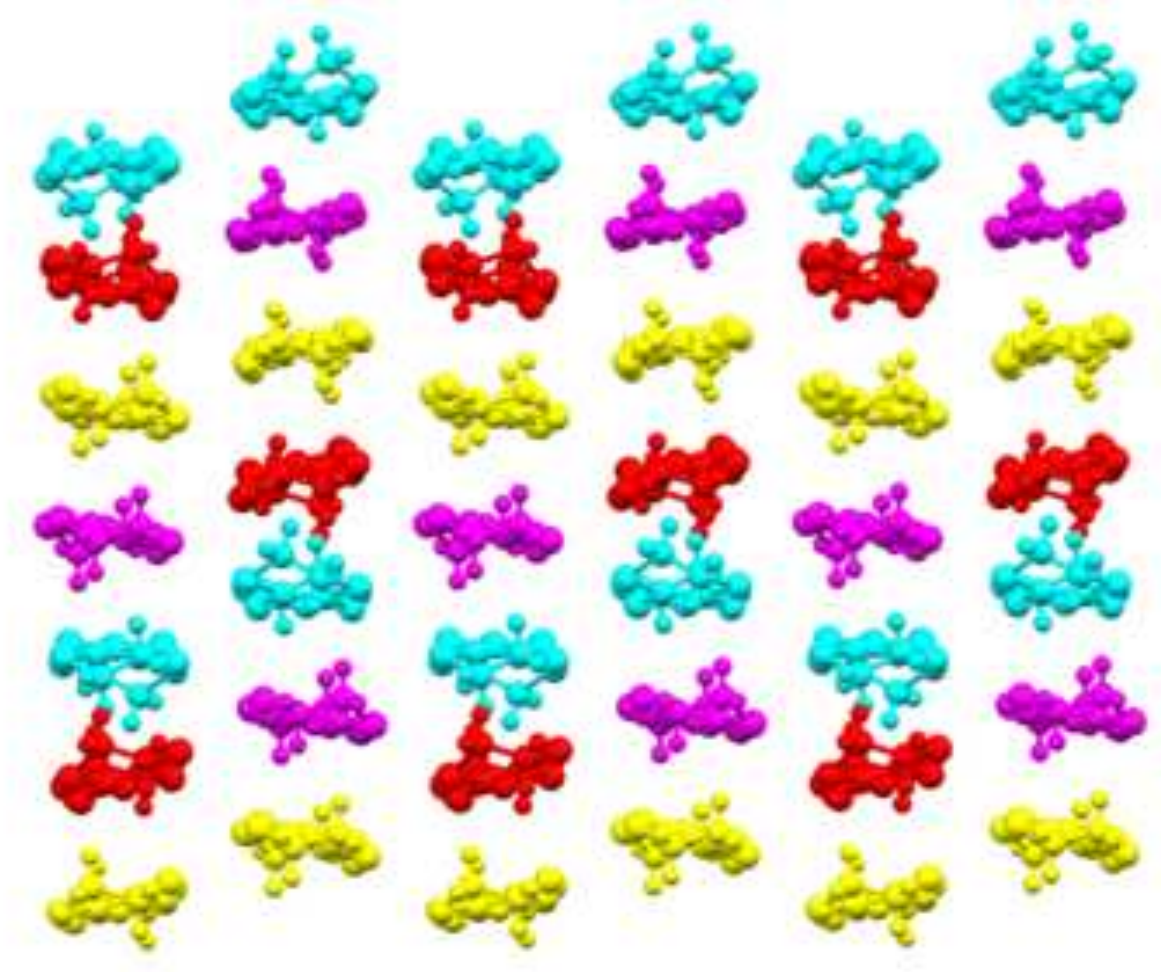




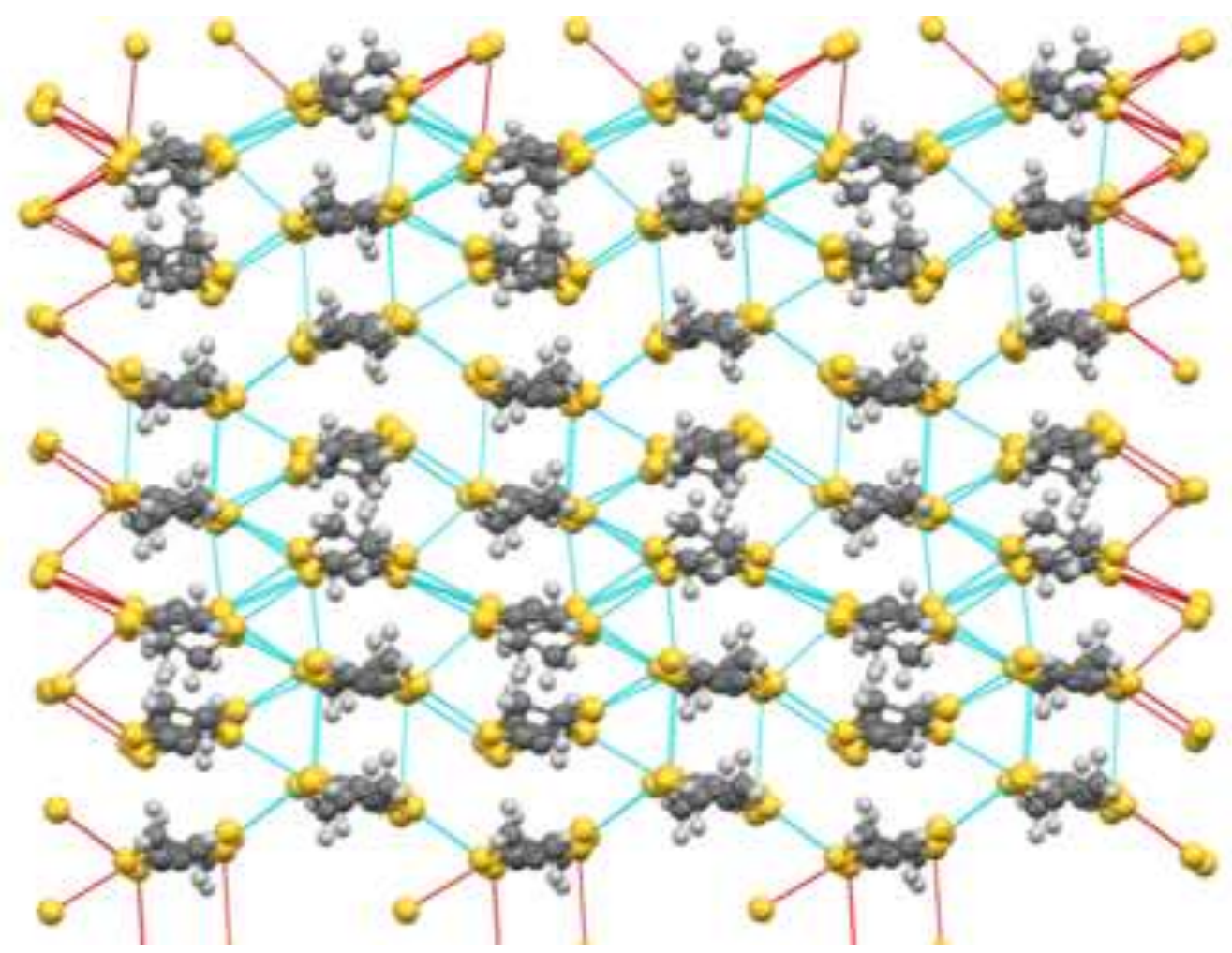


Click here to download high resolution image

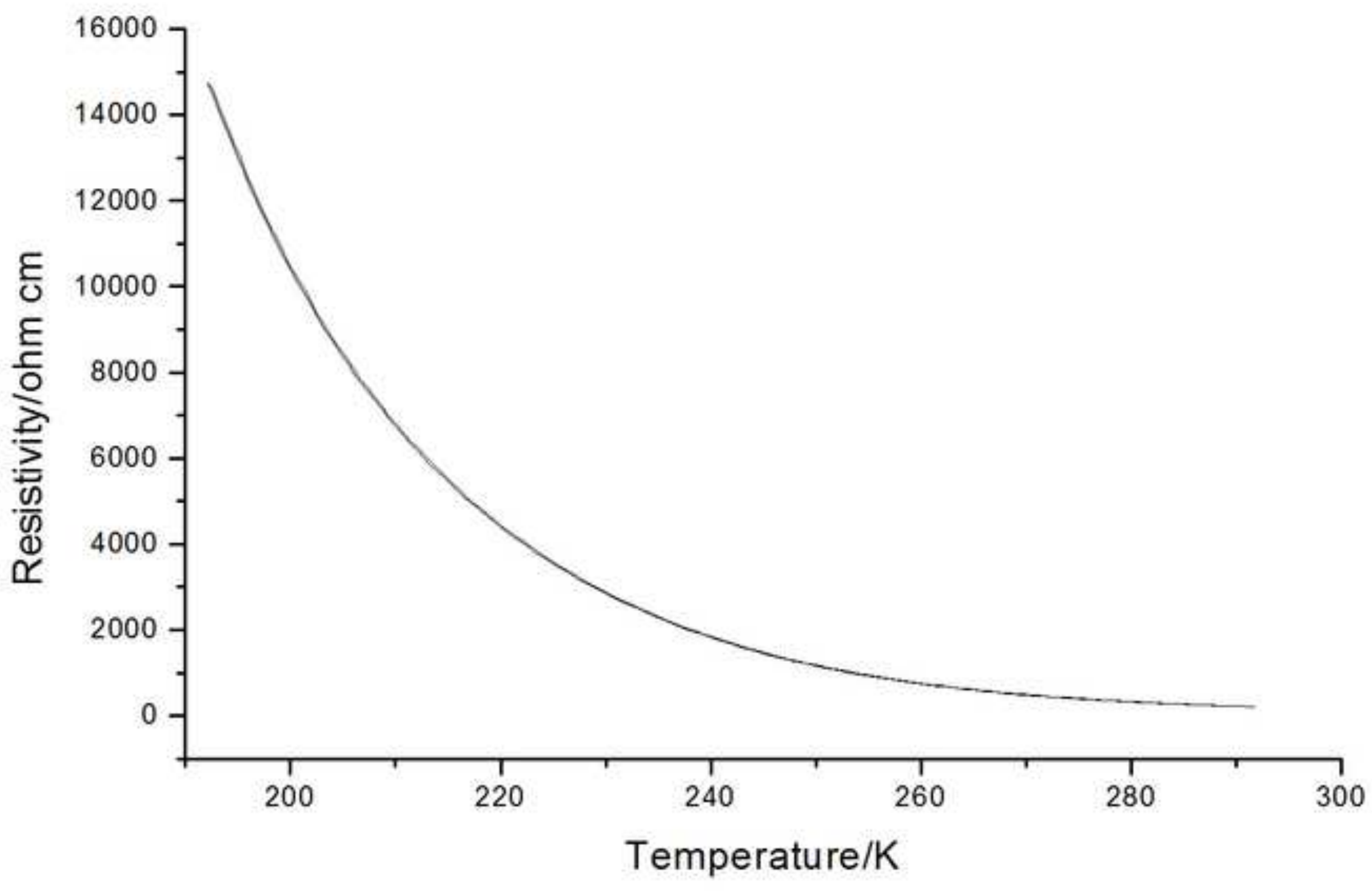

